\title{
Acute confusional state and hyponatraemia due to inappropriate antidiuretic hormone secretion in polyarteritis nodosa
}

\author{
J S H GASTON, D G I SCOTT, AND P A BACON
}

From the Department of Rheumatology, The Medical School, University of Birmingham, Birminghamis

SUMmARY An acute confusional state, which developed in a patient with polyarteritis nodosa (PAN), proved to be secondary to inappropriate secretion of antidiuretic hormone and consequent hyponatraemia. This is a very unusual complication of PAN and may well reflect direct stimulation of the supraoptic nuclei owing to cerebral vasculitis.

Key words: cerebral vasculitis.

The syndrome of inappropriate antidiuretic hormone secretion (SIADH) is well described in association with chest diseases (malignant or inflammatory), disorders of the central nervous system, and certain drugs. ${ }^{1-3}$ In contrast, there have only been two reports of SIADH arising in the context of vasculitic disease; one concerned two patients with temporal arteritis who developed hyponatraemia and an associated confusional state, ${ }^{4}$ whereas the other described a patient with polyarteritis nodosa (PAN) who only had asymptomatic hyponatraemia. ${ }^{5}$ In this report we describe a patient with systemic necrotising arteritis characteristic of PAN who developed an acute confusional state and the typical electrolyte disturbances of SIADH, and who responded rapidly to treatment with high dose corticosteroids.

\section{Case report}

A 64 year old retired engineer presented to his general practitioner with an acute onset of arthralgias involving both peripheral and central joints, stiffness in the sicoulder girdle and lumbar region,

Accepted for publication 4 November 1987.

Correspondence to Dr J S H Gaston, Department of Rheumatology, The Medical School, University of Birmingham, Birmingham B15 2TJ, UK. and immobility. He was treated with anti-⿳亠丷厂巾 inflammatory drugs but continued to deteriorate and after two months was referred to this hospital.o In addition to the presenting symptoms, direct questioning disclosed anorexia and jaw claudication, but he did not complain of headache or visual. disturbance. Examination showed a depressed man in considerable pain, but with the exception of at small, cool effusion in the right knee, there was no 3 . evidence of synovitis, and all joints moved normally. The temporal arteries were non-tender and pulsatile. Laboratory values were as follows: erythrocyte sedimentation rate $125 \mathrm{~mm} / \mathrm{h}, \mathrm{C}$ reactive protein $139^{\circ}$ $\mathrm{mg} / \mathrm{l}$ (normal $<4 \mathrm{mg} / \mathrm{l}$ ), white cell count $26 \cdot 1 \times 10^{9} / 2$ ( $70 \%$ neutrophils), platelets $771 \times 10^{9} / 1$, albumin 22 $\mathrm{g} / \mathrm{l}$, globulins $46 \mathrm{~g} / \mathrm{l}$, alkaline phosphatase $403 \mathrm{IU} / \mathrm{G}$ (normal range 70-350), creatinine $125 \mu \mathrm{mol} / \mathrm{l}$, urean $11.6 \mathrm{mmol} / \mathrm{l}$, creatine kinase normal. Rheumatoid factor was positive (Rose-Waaler titre 1/128); anti $-\frac{}{\sigma}$ bodies to nuclear antigens, extractable nuclear antigens, and to hepatitis $B$ were all negative cryoglobulins were not detected; and protein elece? trophoresis did not show a monoclonal band Electromyography was normal.

A clinical diagnosis of polymyalgia rheumaticad was considered and treatment started empirically with prednisolone $15 \mathrm{mg} / \mathrm{day}$, which resulted in the complete resolution of his stiffness and jaw claudica tion, but after two weeks there was continuing 
malaise, weight loss, and low back pain severe enough to require readmission to hospital. Muscle stiffness and jaw claudication had not recurred. On examination there were no new signs other than increased muscle wasting and epigastric tenderness. Two days later he became restless, confused, and disorientated over a four to six hour period. Cultures of blood, urine, and cerebrospinal fluid were negative, but hyponatraemia was noted (Table 1). At this time the urine had an inappropriately high osmolality $(771 \mathrm{mmol} / \mathrm{kg})$ and contained 73 $\mathrm{mmol} / \mathrm{l}$ sodium. A diagnosis of SIADH was considered and fluid restriction started. While awaiting the results of bacteriological culture he received intravenous cefuroxime without improvement over 12 hours. Corticosteroid dosage was then increased by substituting hydrocortisone $100 \mathrm{mg}$ six hourly intravenously for the prednisolone. After two doses of hydrocortisone he became rational, alert, and orientated, with no memory for the confusional episode. The serum sodium rapidly returned to normal (Table 1).

Further investigation to elucidate the nature of the underlying disease included a muscle biopsy, which showed necrotising vasculitis of small muscular arteries characteristic of PAN (Fig. 1). In addition, there was a markedly raised level of factor VIII related antigen in the serum (over three times normal), consistent with the active endothelial cell damage seen in acute vasculitis. ${ }^{6}$ Arteriography of the coeliac axis and renal vessels did not show aneurysms; cerebral angiography was not performed because of extensive atheroma at the origin of the carotid arteries. Other normal or negative investigations included chest radiographs, barium meal and follow through, and both computed tomographic and ultrasound scans of the abdomen. A diagnosis of PAN was made, and the patient was treated, therefore, with intermittent pulses of cyclophosphamide and steroids, with a rapid improvement in all of his clinical symptoms, including significant weight gain. He has remained completely well with normal renal function and normal blood parameters (white

Table 1 Laboratory values before and after treatment

\begin{tabular}{lllll}
\hline Date & $\begin{array}{l}\text { Na } \\
(\text { mmolll })\end{array}$ & $\begin{array}{l}K \\
(\text { mmolll })\end{array}$ & $\begin{array}{l}\text { Urea } \\
(\text { mmolll })\end{array}$ & $\begin{array}{l}\text { Creatinine } \\
(\mu \text { molll })\end{array}$ \\
\hline First admission & 130 & $4 \cdot 6$ & $11 \cdot 6$ & 125 \\
$\begin{array}{l}\text { Second admission } \\
\text { Confusional state }\end{array}$ & 129 & $5 \cdot 2$ & $7 \cdot 8$ & 109 \\
$\begin{array}{l}\text { 36 Hours after } \\
\text { steroid treatment }\end{array}$ & 129 & $4 \cdot 8$ & $7 \cdot 4$ & 87 \\
$\begin{array}{l}\text { 60 Hours after } \\
\text { steroid treatment }\end{array}$ & 134 & $3 \cdot 3$ & 6.6 & 65 \\
\hline
\end{tabular}

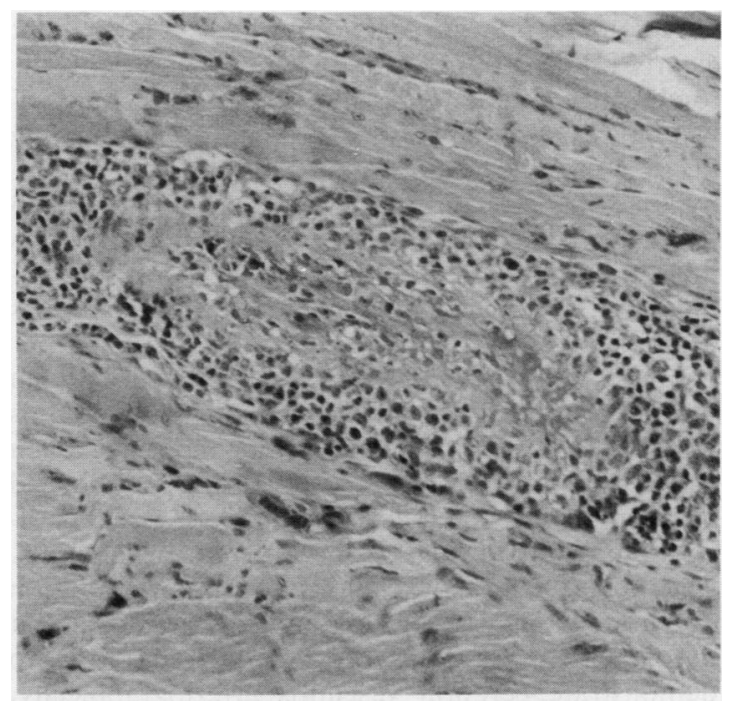

Fig. 1 Haematoxylin and eosin stained section of a small intramuscular artery showing fibrinoid necrosis. A mixed inflammatory cell infiltrate which includes polymorphs and lymphoid cells extends through the vessel wall. The surrounding skeletal muscle fibres show evidence of regeneration.

cell count, platelets, haemoglobin) after four months' follow up.

\section{Discussion}

Some of the presenting features in this case (pain, stiffness, jaw claudication) were suggestive of polymyalgia rheumatica or giant cell arteritis, and these symptoms responded rapidly to low doses of steroids. The overall illness, however, continued to progress rapidly, and the diagnosis of PAN was made from the muscle biopsy, which showed typical necrotising arteritis of small muscular arteries. Very high levels of factor VIII related antigen are more often seen in PAN than in other vasculitides. ${ }^{6}$ The markedly raised white cell count and the increased alkaline phosphatase are also compatible with this diagnosis. It is of interest to speculate whether a biopsy of the temporal arteries (which were always normal on examination) would also have shown a necrotising arteritis rather than giant cell arteritis; this has been reported previously in some patients with PAN. ${ }^{78}$

SIADH has been defined as the occurrence of hyponatraemia, which reflects hypo-osmolality, at a time when the kidneys continue to excrete both a concentrated urine and sodium. Normal renal and adrenal function, with no clinical evidence of 
volume depletion, are also required. ${ }^{1-3}$ Our patient clearly fulfilled this definition: the urine was hypertonic with a high concentration of sodium, hypovolaemia was absent clinically (no diuretics were being taken, and the serum urea decreased with the hyponatraemia), and the patient had already been treated with corticosteroids. Renal function was mildly impaired at presentation, but serum creatinine was in the normal range when SIADH was diagnosed.

There are two principal mechanisms by which hyponatraemia might have been produced in this patient. Firstly, ADH production may have been truly 'inappropriate', caused by pathological stimulation of the supraoptic/hypophyseal pathways, possibly owing to local cerebral vasculitis. The presence of jaw claudication at presentation suggests vasculitis of extracranial vessels, but unfortunately we were prevented from trying to demonstrate cerebral vasculitis arteriographically. The report of SIADH in patients with temporal arteritis, one of whom also had jaw claudication, ${ }^{4}$ supports such a hypothesis, and the rapid response of the hyponatraemia to high dose steroids in our patient could be explained by the expected alleviation of cerebral vasculitis by such treatment. Steroids may also have benefited the disease by direct inhibition of ADH secretion." SIADH apparently due to cerebral vasculitis has been reported in a case of systemic lupus erythematosus studied at necropsy, in which arteritic lesions were noted in the hypothalamus and histological changes in the supraoptic nuclei. ${ }^{10}$

Secondly, the electrolyte abnormalities might have reflected impairment in the ability of the kidneys to excrete water appropriately, without any excess ADH production. This situation commonly arises when the glomerular filtration rate is reduced or there is excessive resorption from the urine before its arrival at the cortical diluting site in the loop of Henle, or both. Under these circumstances the quantity of water excreted is limited by the low volume presented at the collecting tubules. The hyponatraemia of cirrhosis or of congestive cardiac failure is due to such a mechanism, and 'SIADH' associated with chest infections may also occur in this way. In the present case involvement of renal vessels by vasculitis would be postulated, though this was not shown by arteriography, and in the 으 presence of normal urinary sediment and renal function, renal biopsy was not considered justified. $\overrightarrow{\vec{F}}$

The rapidity of the recovery of the hyponatraemia suggests that it was not due to fluid restriction alone, but was more likely to reflect treatment with high $\overline{\bar{N}}$ dose steroids. A similarly rapid response to steroid $\vec{\nabla}$ treatment was reported in a patient with SIADH and temporal arteritis, who regained consciousness ${ }^{\circ}$ after 24 hours' treatment with high dose hydrocorti- $\vec{\circ}$ sone and had a normal serum sodium by 48 hours. ${ }^{4} \vec{\overrightarrow{ }}$ Patients with SIADH complicating chest infection $\vec{\omega}$ also show a rapid recovery when the infection is treated $^{3}$; thus recovery may be dependent on the $\stackrel{0}{\circ}$ treatment of the underlying condition, rather than on a direct effect of steroids on ADH secretion.

This is the first report of SIADH as a major $\vec{N}$ complication of PAN. We suggest that the most ${ }_{\circ}^{\infty}$

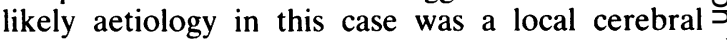
vasculitis stimulating $\mathrm{ADH}$ secretion directly and responding rapidly to treatment with corticosteroids.

We are grateful to Dr G Kondratowicz. Department of Pathology, University of Birmingham, for reviewing the pathological findings in this case, and for providing Fig. 1.

\section{References}

1 Bartter F C. Schwartz W B. The syndrome of inappropriate secretion of antiduretic hormone. Am J Med 1967; 42: 790-806. $\overrightarrow{\bar{O}}$

2 De Troyer A. Demanet J C. Clinical, biological and pathogenic features of the syndrome of inapropriate secretion of antidiur- $\neg$ etic hormone. $Q J$ Med 1976; 45: 521-31.

3 Thomas T H, Morgan D B, Swaminathan R, Ball S, Lee M R. Severe hyponatracmia. Lancet 1978; i: 621-4.

4 Luzar M J, Whisler R L. Hunder G G. Syndrome of inappropriate antidiuretic hormone secretion in association with $\frac{\sigma}{3}$ temporal arteritis. J Rheumatol 1982; 9: 957-60.

5 Fighali S, Jawad I, Frayha R A. Polyarteritis nodosa with inappropriate ADH secretion. Arthritis Rheum 1982; 25: 118-9.

6 Woolf A D, Wakerley G, Wallington T B, Scott D G I, Dieppe

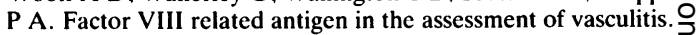

Ann Rheum Dis 1987: 46: 441-7.
7 Morgan G J, Harris E D. Non-giant cell temporal arteritis. O Arthritis Rheum 1978; 21: 362-6.

8 Frayha R A, Abu-Haidar F. Polyarteritis nodosa masquerading $\mathrm{N}$ as temporal arteritis. J Rheumatol 1979; 6: 76-9.

9 Hays R M. Antidiuretic hormone. N Engl J Med 1976; 295: N 659-65.

10 Kaplan A P, Curl F D, Decker J L. Central hyperventilation $\omega$ and inappropriate antidiuretic hormone secretion in systemia lupus erythematosus. Am J Med 1970; 48: 661-7. 